\title{
Manual Reduction of Incarcerated Inguinal Hernia in Children
}

\author{
Thapa $\mathbf{B}^{1}$, Pun $\mathbf{M}^{2}$ \\ 'Dr. Bijay Thapa, MBBS, MS, Registrar, Paediatric Surgeon, ²Dr. Madhusudan Pun, MBBS, DCH. MS, Head of Department, \\ Department of Paediatric Surgery, Kanti Children's Hospital, Maharajgunj, Kathmandu, Nepal.
}

Address of correspondence: Dr. Bijay Thapa, E-mail: bijaytapa@hotmail.com

\begin{abstract}
Introduction: Incarceration of an indirect inguinal hernia in children is an acute emergency and one of the common complications that may occur before herniotomy. Inguinal hernias rarely go away, and therefore, virtually all should be repaired at any age of presentation. Incarcerated inguinal hernia can be reduced successfully by manual reduction if performed by experienced hands on time. The objective of this study was to assess the safety and efficacy of manual reduction of incarcerated indirect inguinal hernia. Materials and Methods: Thirty six patients who attended Emergency Department of Kanti Children's Hospital over 30 months period from January 2009 to July 2011 were studied prospectively. All patients were diagnosed case of inguinal hernia and waiting for elective herniotomy. Results: There were $30(83.33 \%)$ males and $6(16.66 \%)$ females, with male-to-female ratio of 5:1. Right sided inguinal hernia was $20(55.5 \%)$ and left $16(44.44 \%)$. The ages ranged from 1.5 months to 28 months with mean age of 15 months. Time of incarceration ranged from 3 hours to 30 hours. Manual reduction was successful in 30(83.33\%). Remaining six had to undergo emergency surgery. Four patients with edematous but viable hernial contents had successful surgical reduction. Two patients with gangrenous small bowel loops had bowel resection and anastomosis. Conclusion: Manual reduction is safe and effective when performed timely. Herniotomy should be done without delay once diagnosed to avoid unnecessary complications.
\end{abstract}

Key words: Hernia, Manual reduction, Herniotomy

\section{Introduction}

Inguinal hernia repair is one of the most common surgeries performed by paediatric surgeons. Elective hernia repair covers about 20 to $30 \%$ of total daily surgeries in Kanti Children's Hospital. Incarceration of an inguinal hernia is an acute surgical emergency. Incarceration is an entrapment of bowel without vascular compromise. They present with a tense, tender, irreducible lump in either groin and sometimes associated with vomiting ${ }^{1,2,3}$. About $95 \%$ of incarcerated inguinal hernias may be reduced successfully by nonoperative maneuvers of manual reduction called taxis under sedation $4,5,6,7,8,9,10,11$. This study describes our experience of incarcerated inguinal hernia over a period of 30 months at the department of paediatric surgery in Kanti Children's Hospital.

\section{Materials and Methods}

A prospective study of 36 patients with incarcerated inguinal hernia over a period of 30 months from January 2009 to July 2011 who attended the emergency department of Kanti Children's Hospital $(\mathrm{KCH})$ was carried out. All patients were diagnosed cases of inguinal hernia and waiting for elective repair in our register. Each patient was evaluated in regard to age, sex, side of hernia, duration of incarceration to avoid manual reduction for longer time and non-operative and operative management.

The management prior to reduction was keeping the patient in nil per oral, intravenous line with fluids to maintain hydration, blood investigations if surgery is needed and $\mathrm{x}$-ray erect abdomen to see intestinal obstruction and bowel loops in inguinal region. Each patient was given $1 \mathrm{mg} / \mathrm{kg}$ im pethidine.

Counselling and approval from the patients party about the possible risk of manual reduction was taken. After the successful manual reduction patients were observerd overnight to see any complications and disharged with readmision within a week for herniotomy. 
Patients with features of intestinal obstruction on xray, abdominal distension, bloody stool, red tender edematous inguinal mass along with time duration over 30 hours were not attempted for reduction.

\section{Following were the steps of manual reduction:}

1. Patient was kept on supine position with head low and buttock elevated on a normal pillow.

2. Examiner sat on ipsilateral side with left index and middle finger on anterior superior iliac crest. The fingers swept down along the inguinal canal toward the scrotum, keeping constant tension on for optimal alignment of long axis of hernia with the axis of the inguinal canal.

3. The pressure was applied with the right index finger and thumb on the hernia neck.

4. The left hand was put at the apex of the mass and with constant pressure on the inguinal canal from the right index and thumb fingers. The finger was moved slowly up the groin toward internal ring. Constant pressure was on bottom of hernia contents till the contents were reduced to abdominal cavity.

5. The same steps were repeated two to three times in fifteen minutes interval. If the reduction was unsuccessful the emergency surgery was done immediately.

\section{Results}

Of the 36 patients with incarcerated inguinal hernia 30 were males (83.33\%) and 6 females (16.66\%) with male to female ratio of $5: 1$. The mean age of the patient was 15 months with the range of. 1.5 months to 28 months. Twenty patients (55.55\%) in this series were right sided compared $16(44.4 \%)$ on the left sided incarcerated inguinal hernia.

Table 1: Sex distribution of children with incarcerated hernia $(n=36)$

\begin{tabular}{|c|c|c|}
\hline Sex & No. & Percentage \\
\hline Male & 30 & 83.33 \\
\hline Female & 6 & 16.66 \\
\hline Total & $\mathbf{3 6}$ & $\mathbf{1 0 0}$ \\
\hline
\end{tabular}

Table 2: Age distribution of patients $(n=36)$

\begin{tabular}{|c|c|c|}
\hline Age(months) & No. & Percentage \\
\hline $0 \sim 6$ & 4 & 11.11 \\
\hline $6 \sim 12$ & 8 & 22.22 \\
\hline $12 \sim 18$ & 12 & 33.33 \\
\hline $18 \sim 24$ & 6 & 16.66 \\
\hline$>24$ & 6 & 16.66 \\
\hline Total & $\mathbf{3 6}$ & $\mathbf{1 0 0}$ \\
\hline
\end{tabular}

Table 3: Relationship between sex and side of incarcerated hernia in children.

\begin{tabular}{|c|c|c|c|c|c|c|}
\hline Side & \multicolumn{2}{|c|}{ Male } & \multicolumn{2}{c|}{ Female } & \multicolumn{2}{c|}{ Total } \\
\hline Right & 16 & $44.44 \%$ & 4 & $11.11 \%$ & 20 & 55.56 \\
\hline Left & 14 & $38.88 \%$ & 2 & $5.55 \%$ & 16 & $44.44 \%$ \\
\hline Total & $\mathbf{3 0}$ & $\mathbf{8 3 . 3 3 \%}$ & $\mathbf{6}$ & $\mathbf{1 6 . 6 6 \%}$ & $\mathbf{3 6}$ & $\mathbf{1 0 0 \%}$ \\
\hline
\end{tabular}

Table 4: Distribution of patients by age and sex

\begin{tabular}{|c|c|c|c|c|c|c|}
\hline \multirow{2}{*}{ Age (months) } & \multicolumn{3}{|c|}{ Male } & \multicolumn{2}{c|}{ Female } & \multicolumn{2}{c|}{ Total } \\
\cline { 2 - 7 } & No. & \% & No. & \% & No. & \% \\
\hline $0 \sim 6$ & 4 & $11.11 \%$ & 0 & 0 & 4 & $11.11 \%$ \\
\hline $6 \sim 12$ & 7 & $19.44 \%$ & 1 & $2.77 \%$ & 8 & $22.22 \%$ \\
\hline $12 \sim 18$ & 10 & $27.77 \%$ & 2 & $5.55 \%$ & 12 & $33.33 \%$ \\
\hline $18 \sim 24$ & 5 & $13.88 \%$ & 1 & $2.77 \%$ & 6 & $16.66 \%$ \\
\hline $24 \sim$ & 4 & $11.11 \%$ & 2 & $5.55 \%$ & 6 & $16.66 \%$ \\
\hline Total & $\mathbf{3 0}$ & $\mathbf{8 3 . 3}$ & $\mathbf{6}$ & $\mathbf{1 6 . 6}$ & $\mathbf{3 6}$ & $\mathbf{1 0 0 \%}$ \\
\hline
\end{tabular}


Table 5: Relationship between duration of incarceration and outcome of reduction

\begin{tabular}{|c|c|c|c|c|c|}
\hline \multirow{2}{*}{ Time (hours) } & \multirow{2}{*}{$\begin{array}{c}\text { No; } \\
(\mathbf{n = 3 6 )}\end{array}$} & \multicolumn{2}{|c|}{ Successful reduction } & \multicolumn{2}{c|}{ Unsuccessful reduction } \\
\cline { 3 - 6 } & 17 & No. & \% & No. & \% \\
\hline $0 \sim 6$ & 17 & $47.22 \%$ & 0 & 0 \\
\hline $6 \sim 12$ & 11 & $27.77 \%$ & 1 & $2.77 \%$ \\
\hline $12 \sim 18$ & 3 & 1 & $5.55 \%$ & 1 & $2.77 \%$ \\
\hline $18 \sim 24$ & 3 & 0 & $2.77 \%$ & 2 & $5.55 \%$ \\
\hline $24 \sim 30$ & 2 & $\mathbf{3 0}$ & $\mathbf{8 3 . 3} \%$ & 2 & $5.55 \%$ \\
\hline Total & $\mathbf{3 6}$ & & & $\mathbf{6}$ & $\mathbf{1 6 . 6}$ \\
\hline
\end{tabular}

Table 6: Relationship between sex and outcome of reduction

\begin{tabular}{|c|c|c|c|c|}
\hline \multirow{2}{*}{ Sex } & \multicolumn{2}{|c|}{ Successful reduction } & \multicolumn{2}{c|}{ Unsuccessful reduction } \\
\cline { 2 - 5 } & No. & \% & No. & $13.88 \%$ \\
\hline Male & 25 & $69.44 \%$ & 5 & $2.77 \%$ \\
\hline Female & 5 & $13.88 \%$ & 1 & $\mathbf{1 6 . 6 \%}$ \\
\hline Total & $\mathbf{3 0}$ & $\mathbf{8 3 . 3} \%$ & $\mathbf{6}$ & \\
\hline
\end{tabular}

\section{Discussion}

Inguinal hernia doesn't resolve spontaneously and must be repaired timely because of high risk of incarceration. The inguinal hernia repair is one of the most frequently performed surgical procedures in infancy and childhood. Herniotomy is a simple, safe procedure that can be performed electively as a day care surgery. But if it is incarcerated and manual reduction is not successful the surgery is risky and may even need resection of bowel as two of our patients needed ${ }^{1,7}$.

The incidence of paediatric inguinal hernia reported in literature ranges between $0.5 \%$ and $4.4 \%$.The male to female ratio of $5: 1$ noted in this article agrees with that quoted in literature (3:1 to $10: 1)$, as does the higher incidence of right sided occurrence ${ }^{1,3,13}$.

There is still a controversy in regard of timing of surgery after the diagnosis and the timing of herniotomy has not been precisely defined ${ }^{5}$. Delaying in herniotomy in infants is still commonly practiced in the poor medical set up of our country. This is mainly due to two reasons. Firstly patients party are not willing to do surgery in infancy and secondly not all medical centres in Nepal are capable of performing herniotomy in infancy due to less experience and high risk in pediatric population. This delay in surgery may lead to incarceration of inguinal hernia after diagnosis

In our series $66.6 \%$ of incarcerated hernia were under the age of 18 months of age. This shows majority of incarceration occurs in small age. The incidence of inguinal hernia and incarceration at this age is due to the presence of congenital sac which will fill when sufficient intra-abdominal pressure exists. It is also this age at which children begin to stand and walk ${ }^{6}$.
Stephens et al recommended hernia repair should be done within seven days of diagnosis on a semi-elective basis ${ }^{5}$. This seems not as feasible in our system as there are very few centers performing pediatric surgery. As Kanti Children's Hospital is one of the main tertiary centre for paediatric surgery cases, there are many children who need to undergo various types of surgeries in this hospital. So patients with inguinal hernia are not able to get an early appointment for surgery. All 36 patients in this series were a diagnosed as a case of hernia waiting for repair. This complication is preventable if surgery is performed on time.

Although incarceration of an inguinal hernia is a common complication, majority of them can be reduced by non-operative manual reduction of taxis. Thirty patients $(83.3 \%)$ in our study had successful manual reduction. Only $16.6 \%$ had to undergo emergency surgery and during the surgery, the hernial contents were found to be healthy small bowels (4) which were reduced and then herniotomy performed. Only two cases with more than 24 hours of incarceration had to undergo bowel resection. This showed that the chances of strangulation in paediatric hernia is low but increases with longer the duration of incarceration.

Rowe and Clatworthy noted only 5/355 cases of bowel injury in cases of incarceration without surgery ${ }^{15}$. Mac Lehnans personal series showed only 4/1038 cases of strangulation during hernia operations.

The mechanism by which the children bowel is protected is uncertain. The reason behind this is the abdominal wall in children is not well developed; tissues around inguinal canal, external ring, and internal ring are soft so that pressure to the canal becomes weaker for 
vascular compromise. In addition the elasticity of blood vessels is better therefore damage to blood circulation occurs late. This mechanism makes manual reduction possible despite longer duration of incarceration ${ }^{7,10,15}$.

Thorndilike and Ferguson in 1938 stated that attempt of manual reduction by pressure are dangerous and illogical without surgery ${ }^{16}$. But this management plan is widely practiced and there are few reports of complications. Our study also verifies this technique applied with caution is frequently successful and we saw no complication with its practice.

\section{Conclusion}

Incarceration of indirect inguinal hernia and its complications are preventable if early herniotomy is done after diagnosis and without any delay. Manual reduction of taxis in children is safe and effective when performed in clinically stable patients by expert hands.

\section{Acknowledgements: None \\ Funding: Nil \\ Conflict of Interest: Nil \\ Permission from IRB: Yes}

\section{References}

1. Stylianos $\mathrm{S}$, Jacir NN, Harris BH. Incarceration of inguinal hernia in infants prior to elective repair. $J$ Pediatr Surg 1993;28(4):582-3.

2. Niedzielski J, Kr I R, A. Could incarceration of inguinal hernia in children be prevented? Med Sci Monit 2003;9(1):16-8.

3. Ameh EA. Incarcerated and strangulated inguinal hernias in children in Zaria, Nigeria. East Afr Med J 1999;76(9):499-501.

4. G. Smith and J. E. Wright, Reduction of gangrenous small bowel by taxis on an inguinal hernia. Pediatr Surg Intern 1996;11(8):582-83.
5. Stephens BJ, Rice WT, Koucky CJ, Gruenberg JC. Optimal timing of elective indirect inguinal hernia repair in healthy children: clinical considerations for improved outcome. World J Surg 1992;16(5):952-7.

6. BV Plamer. Inacarcerated inguinal hernia in children. Ann Royal Coll Surg Eng 1978;60:121-24.

7. N. Brindley, R. Taylor and S. Brown, Reduction of incarcerated inguinal hernia in infants using caudal epidural anesthesia. Pediatr Surg Intern 2005;21(9):715-17.

8. ZTurkyilmaz, KSonmez. Incarcerated inguinal hernia in children. Hong Kong J Emerg Med 2010;17:244249.

9. Chandra Shekhar Agrawal and Akshay Pratap. Pediatric Inguinal Hernia: Controversies and decision making. Nepal Med Coll J 2007;9(3):199-203.

10. Jamshed Akhtar, Abdul Salam. Irreducible inguinal hernia in children. Pak J Surg 1998;14:34-36

11. Bilge Karabulut. One surgeon experiences in childhood inguinal hernias. J Korean Surg Soc 2011;81:50-53.

12. Nah SA, Giacomello L, Eaton S. Surgical Repair of Incarcerated Inguinal Hernia in Children: Laparoscopic or Open? Eur J Pediatr Surg 2011;46(9):1868-69.

13. John C. Eze, Enugu. Obstructed Inguinal Hernia: Role of technical Aid Program. Nati Med Assoc 2004;96:850-52.

14. Ali M. AISaiegh. Surgey for inguinal hernia in infancy and childhood. Kufa Med J 2007;10:1-9.

15. Rowe MI, Clatworthy HW. Incarcerated and strangulated hernia in children. A statistical study of high-risk factors. Hong Kong Med J 1998;4:199-211.

16. Thorndike A, and Ferguson, CF. Incrcerated inguinal hernia in infancy and childhood. Am J Surg 1938;39(2):429-437.

\section{How to cite this article ?}

Thapa B, Pun M. Manual Reduction of Incarcerated Inguinal Hernia in Children. J Nepal Paediatr Soc 2012;32(3):229-232. 